\title{
Juliane Brauer, Zeitgefühle. Wie die DDR ihre Zukunft besang. Eine Emotionsgeschichte.
}

\section{Emmanuel Droit}

\section{OpenEdition}

\section{Journals}

Electronic version

URL: https://journals.openedition.org/ifha/11569

DOI: 10.4000/ifha.11569

ISSN: 2198-8943

\section{Publisher}

IFRA - Institut franco-allemand (sciences historiques et sociales)

\section{Electronic reference}

Emmanuel Droit, "Juliane Brauer, Zeitgefühle. Wie die DDR ihre Zukunft besang. Eine

Emotionsgeschichte.", Revue de l'IFHA [Online], Date of review, Online since 07 December 2021, connection on 09 December 2021. URL: http://journals.openedition.org/ifha/11569 ; DOI: https:// doi.org/10.4000/ifha. 11569

This text was automatically generated on 9 December 2021.

(C)IFHA 


\section{Juliane Brauer, Zeitgefühle. Wie die DDR ihre Zukunft besang. Eine} Emotionsgeschichte.

Emmanuel Droit

\section{REFERENCES}

Juliane Brauer, Zeitgefühle. Wie die DDR ihre Zukunft besang. Eine Emotionsgeschichte, Transcript Verlag, Bielefeld, 2020, 430 p., $45 €$. 
En 2004, dans un article roboratif publié dans la revue Zeithistorische Forschungen, Thomas Lindenberger appelait de ses vœux une mutation de l'histoire du temps présent encore trop centrée, selon lui, sur les expériences politiques des contemporains. Il invitait notamment les historiens à réfléchir à la manière dont les Mitlebenden faisaient l'expérience du monde qui les entourait, notamment en s'intéressant à la manière dont ces derniers produisaient et consommaient tant du son que de l'image.

Quinze ans plus tard, Juliane Brauer, historienne et musicologue de formation, entreprend le pari très ambitieux de renouveler le champ historiographique consacré à l'analyse de la RDA. Après avoir réalisé un doctorat sur la musique dans le camp de concentration de Sachsenhausen,

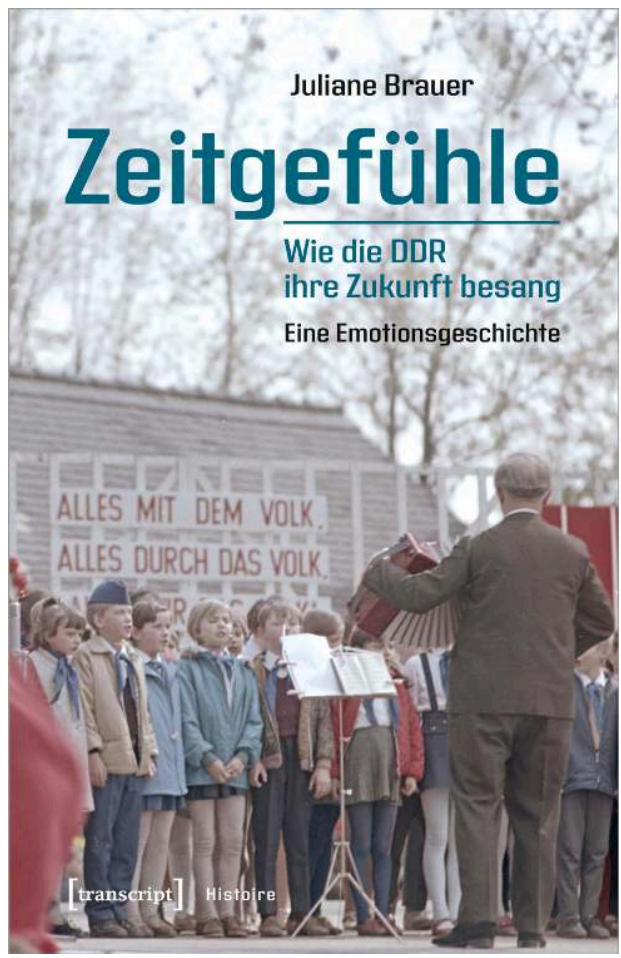
elle cherche à montrer la plus-value heuristique de l'histoire des émotions pour un objet d'étude qui recherche depuis plusieurs années un second souffle. Après avoir connu d'intenses débats épistémologiques au milieu des années 1990 marqués par une opposition rapidement dépassée entre une approche totalitariste et une histoire socio-culturelle des pratiques, la production scientifique a trouvé un équilibre avec la mise en œuvre d'une histoire sociale de la domination politique qui s'est traduite tant en Allemagne qu'à l'étranger par un nombre important de travaux de qualité (Lindenberger, Kott, Palmowski, Rubin, Christian, Rowell, Port).

Dans le sillage d'une histoire des émotions désormais bien établie en Allemagne, Juliane Brauer propose une lecture sinon inédite du moins originale de la RDA. Sans apporter nécessairement des conclusions qui renouvellent fondamentalement le regard qu'on peut avoir sur ce régime de dictature et son système d'encadrement de la jeunesse, son enquête a le mérite de croiser deux enjeux qu'on rencontre rarement dans la production historiographique sur la RDA : d'un côté, une analyse très fine du régime d'historicité futuro-centré mis en œuvre par les communistes est-allemands et de l'autre, une étude globale du répertoire de chansons destinés à faire advenir l'homme socialiste nouveau. Au croisement de l'histoire de l'éducation et de l'histoire des émotions, le livre est structuré en six chapitres chronologico-thématique couvrant de manière inégale les années 1945-1973. Chaque moment met l'accent sur une manière bien particulière de ressentir la musique et les paroles, elles-mêmes réinscrites dans la tradition des mouvements de jeunesse socialistes de l'entre-deux-guerres, une histoire comparée avec les mouvements de jeunesse en RFA et une socio-histoire du Politique attentive aux conflits internes et aux évolutions qui traversent les institutions de cette « dictature éducative » (Wierling). Ainsi, à partir de l'analyse de chansons à destination des jeunes pionniers (Heimatlied, Wir wohnen all in einem Haus, Thälmannlied), J. Brauer met successivement en avant une idée force: la nouveauté dans le contexte de la 
société de l'effondrement (1945-1949), le futur (1950-1951), le patriotisme (1952-1961), la confiance (1961-1965), l'authenticité (1960-1973) et la conscience de soi (1973). Cette palette d'émotion correspond évidemment aux attentes normatives du régime et non à la manière dont les chansons ont vraiment été reçues par la jeunesse de RDA. A ce stade, J. Brauer ne peut émettre que des hypothèses plausibles reposant sur le lien entre émotions, expériences collectives et mémoire.

Elle revisite les grandes manifestations organisées par la jeunesse contre la rencontre de la jeunesse de 1961 ou la Jugendweihe, ce grand rituel de passage à l'âge adulte célébré à partir de 1954 par tous les adolescents âgés de 14 ans. Le contexte politique et musical dans lequel émergent ce répertoire de chansons est soigneusement reconstruit. On retrouve là sans surprise les acteurs attendus d'une histoire de la domination politique : les commissions et les départements des ministères, du SED et du conseil central de la FDJ. Pour la décennie 1950, J. Brauer montre de manière convaincante que les chansons des pionniers relatives à l'amour de la patrie, à l'admiration vouée pour Ernst Thälmann ou la fierté éprouvée envers les « soldats de la paix » étaient davantage des appels à l'action que des textes faisant appel aux émotions des enfants. Par contre, les émotions étaient au cœur du projet du mouvement de chants de la FDJ développés dans les années 1960 car les chansons étaient articulées à des histoires incarnées, à des destinées individuelles de héros antifascistes qui ont été victimes de la répression nazie. Le chapitre consacré à l'année 1973 permet enfin à J. Brauer de souligner l'essoufflement du régime d'historicité futuro-centré voire même son érosion. En ce sens, cet effet de seuil mériterait d'être mis en perspective avec la crise de confiance dans les catégories de progrès et de croissance que l'on observe en Europe de l'Est après le premier choc pétrolier et les débuts du processus de déindustrialisation.

$\mathrm{Au}$ final, l'histoire des émotions, sans apporter fondamentalement de résultats inédits, constitue un complément très utile à la compréhension des intentions normatives du régime est-allemand.

\section{INDEX}

Subjects: Histoire culturelle

Chronological index: Epoque contemporaine

\section{AUTHOR}

EMMANUEL DROIT

Sciences Po Strasbourg 